\title{
O PAPEL DOS PAIS NA ESCOLARIZAÇÃO DOS FILHOS COM PERTURBAÇÃO DA APRENDIZAGEM ESPECÍFICA COM DÉFICE NA LEITURA ${ }^{1}$
}

\author{
Alexandra Gonçalves ${ }^{2}$ \\ Célia Ribeiro ${ }^{3}$
}

\begin{abstract}
Resumo: A Perturbação da Aprendizagem Específica com défice na leitura carateriza-se por um padrão de leitura em que se verifica, fundamentalmente, desde as primeiras fases de aprendizagem, uma grande dificuldade na identificação das palavras escritas.

Sendo as competências de leitura e escrita essenciais para a aprendizagem e para o sucesso escolar, torna-se imperioso que o diagnóstico seja realizado atempadamente, de forma a proporcionar estratégias educativas adequadas, que aplicadas de forma sistemática e permanente, contribuirão para que os alunos com a perturbação em causa vejam facilitada a aprendizagem $e$ o desenvolvimento do processo de leitura e de escrita.

Consideramos que os pais e os professores de educação especial devem agir como uma equipa e encetar um trabalho conjunto $e$ planeado, que permitirá incrementar atividades/estratégias que ajudarão a desenvolver a capacidade de autonomia e o sentido de responsabilidade dos alunos com Perturbação da Aprendizagem Específica com défice na leitura. A revisão da literatura efetuada aponta para a importância de uma intervenção especializada regular, com medidas educativas adequadas e com a colaboração dos pais/encarregados de educação.
\end{abstract}

\footnotetext{
${ }^{1}$ Este artigo retoma, parcialmente, a revisão da literatura da Dissertação de Mestrado em Ciências da Educação, Especialização em Educação Especial, apresentada ao Centro Regional de Viseu da Universidade Católica Portuguesa, em 2016.

2 Mestre em Ciências da Educação, Especialização em Educação Especial, pelo Centro Regional de Viseu da Universidade Católica Portuguesa. Docente de Educação Especial. E-mail: alexandrarodrigues_01@ @otmail.com

3 Doutorada em Psicologia. Professora Auxiliar do Centro Regional de Viseu da Universidade Católica Portuguesa. E-mail: cribeiro@ viseu.ucp.pt
} 
Palavras-chave: Perturbação da Aprendizagem Específica com défice na leitura; Pais/encarregados de educação; Professores de educação especial; Intervenção; Colaboração; Sucesso escolar.

\title{
Title: THE ROLE OF PARENTS IN SCHOOLING OF CHILDREN WITH SPECIFIC LEARNING DISORDER WITH IMPAIRMENT IN READING
}

\begin{abstract}
The Specific Learning disorder with impairment in Reading is characterized by a reading pattern in which we can see, essentially from the first stages of learning, a great difficulty in identifying written words.

Being the reading and written skills crucial for learning and for the school success, it is imperative that the diagnosis is done on due time so that the proper educational strategies can be provided. Applied in a systematic and permanent way, they will enable learning and the development of reading and writing skills in students with this disorder.

We are aware that parents and Special Education teachers should act as a team and start a planned co-work which will allow the development of strategies that will help the development of autonomy and the sense of responsibility of students with Specific Learning disorder with impairment in Reading. The literature revision that was done points to the importance of regular specialized intervention, with suitable educational measures and the cooperation of parents/guardians.
\end{abstract}

Keywords: Specific Learning disorder with impairment in Reading; Parents/guardians; Special Education teachers; Intervention; Cooperation; Students' success.

\section{INTRODUÇÃO}

Revendo a literatura, verificamos que a análise da relação entre a escola e as famílias tem aumentado exponencialmente nos últimos anos e constitui-se como uma relação complexa e multifacetada. Silva (2003) salienta que nesta relação se está, essencialmente, à defesa, uma vez que "tanto pais como professores não estão habituados a colaborar - apesar da crescente pressão nesse sentido. "Nem uns nem outros foram previamente preparados para tal" (p. 389). Se por um lado, "os professores convivem com a proliferação de novos papéis e de novos contextos de intervenção que, por sua vez, apelam para novas práticas", por outro, as famílias 
veem-se "constrangidas" a participar num contexto (o escolar) que tinham "aprendido" não ser seu, sem que lhes seja "ensinado" como agir" (p. 389).

Argumenta-se no sentido de verificar resultados positivos para os alunos de um estreitamento de relações entre docentes e pais, sendo que tem sido bastante relatada "a forte correlação positiva que se tem encontrado entre o envolvimento parental e o sucesso educativo dos seus filhos" (Silva, 2003, p. 27). Neste sentido, o autor aponta para "a necessidade de uma articulação entre dois tipos de educação e os seus agentes preferenciais, pais e professores" (p. 57).

Os pais, enquanto colaboradores e/ou parceiros, podem atuar de forma individual ou assumir uma intervenção coletiva e organizada, pois sãolhes reconhecidas competências com algum grau de equidade ou de complementaridade. Para o autor é suposto que a colaboração traga benefícios para os educandos "filhos em casa, alunos na escola" (Silva, 2003, p. 57).

O diálogo positivo e a partilha de responsabilidades educativas tornam mais fácil e satisfatório o trabalho do professor, sendo estes mais valorizados e alvo de maiores simpatias por parte dos pais (Marques, 1997).

Assim, o presente artigo tem como objetivo evidenciar que, quando as escolas criam um clima escolar positivo, promovendo uma estrutura para o envolvimento dos pais, estas resultam como um elo de ligação entre a escola e a família. Este elo implica obrigações e responsabilidades para ambas as partes, em colaboração contínua, sendo certo de que quem beneficia são os alunos, em especial os alunos com Perturbação da Aprendizagem Específica (PAE), que necessitam de um apoio especializado regular, contribuindo para o seu êxito escolar e vida futura.

\section{COORDENAÇÃO ENTRE AGENTES EDUCATIVOS: PROFESSOR/ PAIS}

Estamos cientes de que o desenvolvimento de uma criança começa no seio de uma família e que, progressivamente, as relações que estabelece com o meio envolvente se estendem a outros contextos. Partindo do Modelo Ecológico do Desenvolvimento Humano, desenvolvido por Bronfenbrenner (1979), que situa a criança no centro de um sistema ecológico, caracterizado por uma rede de trocas e relações, a abordagem 
da relação escola - família parece-nos essencial, visto que são contextos da vida da criança que desempenham um papel crucial no seu desenvolvimento, sobretudo no caso de crianças com necessidades educativas especiais. Bronfenbrenner (1979) apresenta um conjunto de sistemas, caracterizados por trocas dinâmicas e recíprocas entre um sujeito ativo e diferentes contextos em permanente transformação: microssistema, mesossistema, exossistema e macrossistema.

O microssistema engloba um conjunto de ambientes em que a criança está imersa e as experiências entre ela e as restantes pessoas que a rodeiam num contexto imediato - família, escola, grupo de pares, comunidade. O mesossistema é definido por interrelações entre dois ou mais sistemas - família - escola, escola - comunidade. O exossistema engloba os contextos nos quais a criança não participa diretamente mas onde podem ocorrer factos que exercem influência ou são influenciados por ela - serviços de saúde, meios de comunicação social, serviços jurídicos. O macrossistema integra os sistemas anteriores e representa os valores e crenças culturais da sociedade em que a criança está inserida que afetam ou determinam o complexo de estruturas e atividades que ocorrem nos níveis mais concretos - leis laborais (Bronfenbrenner, 1979).

Desta forma, os contextos família, escola e ainda a comunidade, em colaboração, constituem apoios significativos na educação de alunos com PAE.

Ao longo dos últimos anos, tem-se vindo a constatar que a relação estabelecida entre os pais e os professores foi admitindo algumas mudanças, evoluindo para uma relação de maior proximidade, tornando desejável uma colaboração estreita entre estes dois agentes educativos (Diogo, 1998). Azcue (2012) refere também as transformações que ao longo do tempo tem sofrido a relação escola - família, "evoluindo de uma relação unilateral, na qual era atribuído um papel mais passivo aos pais, para uma relação de maior proximidade e colaboração estreita entre família e escola" (p. 31).

Há quem refira que é aos professores que cabe a responsabilidade de dar os primeiros passos que permitam uma verdadeira colaboração. Outros, pelo contrário, defendem que a implicação dos pais é demasiado importante para que a iniciativa seja atribuída apenas aos professores (Montandon, 1996). Desta forma, "a comunicação constitui um dos elementos fundamentais para um estabelecimento de relações de parceria no trabalho a desenvolver com os pais" (Correia, 2008, p. 162). Simpson (1990, como citado em Correia, 2008) refere que "as estratégias básicas 
para melhorar a comunicação entre pais e profissionais são a confiança e o respeito, elementos essenciais para uma comunicação produtiva e significativa entre famílias e profissionais" (p. 162).

Marques (1991) afirma que "pais que se envolvem na educação dos próprios filhos e que comunicam de forma positiva com os professores, tendem a encarar o professor com mais simpatia e apreço" (p. 68), sendo que quando "os pais acompanham e ajudam o trabalho dos filhos, estes têm melhores resultados do que os colegas com idêntico background mas cujos pais se mantêm afastados da escola" (Marques, 1997, p. 6). Neste sentido, os pais conhecem melhor o processo educativo dos seus educandos, podendo prestar-lhes um apoio mais sustentado dando continuidade aos trabalhos desenvolvidos pelos professores. Sendo os pais os parceiros mais importantes na educação das crianças, "uma boa sincronização entre pais e escola representa meio caminho andado" (Azcue, 2012, p. 34).

Assim, trabalhando em conjunto, pais e professores poderão facultar ao aluno uma igualdade de oportunidades. Escola e família "só podem ter um objetivo em comum: otimizar o desenvolvimento da criança em todos os aspetos. Caso contrário, ambos caminharão de forma transversal" (Azcue, 2012, p. 34).

Desta forma, Estanqueiro (2013) admite que "uma boa relação entre a família e a escola aproxima pais e filhos, melhora a confiança entre pais e professores, reforça a motivação para estudar, previne a indisciplina e aumenta o sucesso" (p. 63).

Não obstante, nem sempre se verifica uma efetiva aproximação por parte da família à escola. Estamos conscientes de que os nossos dias estão marcados pelo tempo escasso que os pais têm para oferecer aos filhos. Estão demasiadamente ocupados, descurando que a escola precisa do seu apoio para educar e para auxiliar os alunos na superação das suas dificuldades para que possam progredir de forma salutar (Sampaio, 1996).

Parece ser ponto assente que a família e a escola são os dois contextos de desenvolvimento privilegiados e quando todos colaboram, o sucesso é garantido.

Deste modo, pede-se aos pais que encorajem as aprendizagens escolares dos filhos e aos professores que "estabeleçam uma colaboração estreita com as famílias a fim de melhor situar as crianças no seu meio e de suscitar o envolvimento dos pais nos assuntos da escola e nas atividades escolares dos filhos" (Sousa, 1998, p. 145). 
É impossível pôr à parte escola, família e comunidade, pois, se o sujeito é o aluno, filho e cidadão, ao mesmo tempo, a tarefa de ensinar não compete apenas à escola, porque o aluno aprende também através da família, dos amigos, das pessoas que ele considera importantes. É indispensável que família e escola se olhem responsavelmente como parceiras de caminhada, pois ambas são responsáveis pelo que produzem, podendo reforçar ou contradizer a influência uma da outra. A construção de equipas, onde a família também está presente é essencial para implementar um modelo inclusivo. Os pais são parceiros básicos no processo de inclusão da criança na escola, as mudanças que ocorrem na escola deverão ser introduzidas a partir dos debates/reuniões com a equipa técnica, os alunos, pais e professores.

Salienta-se o facto de existir no $1^{\circ}$ ciclo um sistema de monodocência que leva a que os pais possam estabelecer uma relação de maior proximidade, o que possibilita um maior conhecimento dos alunos e das suas famílias, promovendo o envolvimento parental. É mais fácil estabelecer relações informais, porque os pais aproveitam quando acompanham os filhos à escola para "dar uma palavrinha" ao professor (Zenhas, 2006).

Neste sentido, e segundo alguns autores como Sousa (1998) e Davies, Fernandes, Soares, Lourenço, Costa, Villas-Boas, Vilhena, Oliveira, Dias, Silva, Marques e Lima (1989), a aprendizagem dos alunos é mais significativa e com maior sucesso quando se processa num ambiente em que professores e pais colaboram. Num estudo em que professores são entrevistados, Lareau (1989, como citada em Silva, 2003) conclui "que não constitui uma surpresa saber que os professores sentem que a participação parental na escolarização melhora o desempenho educativo das crianças" (p. 117). Contudo, considera surpreendente "aprender que o envolvimento parental na escolarização influencia a satisfação profissional dos professores (...). Desta forma, as relações escola-família parecem modelar não apenas a experiência escolar das crianças, mas também as dos seus professores" (p. 117). A referida autora constata, ainda, "que os pedidos dos professores para o envolvimento parental em educação sofreram uma escalada nas décadas recentes" (Lareau, 1989, como citada em Silva, 2003, p. 117).

Nesta linha de ideias, também Hulsebosch (1991, como citada em Silva, 2003) desenvolveu um estudo em que distingue os low involvement teachers e os high involvement teachers. Os primeiros envolvem pouco os pais e possuem uma perspetiva pedagógica que remete para um processo 
de ensino e aprendizagem centrado no professor. Por sua vez, os segundos apontam para um processo educativo mais centrado no aluno, com objetivos de desenvolvimento global onde a noção de desenvolvimento da autonomia da criança se revela importante. A autora constata que estes professores se mostram "mais próximos de descrever os pais em termos positivos e as relações com os pais como um recurso para a educação da criança" (Hulsebosch, 1991, como citada em Silva, 2003, p. 118).

Segundo Benavente (1990, como citada em Silva, 2003, p. 66), "os pais são os actores mais "recentes" da questão escolar". A escola tem vindo a entender o estreitamento de relações com as famílias no sentido do apoio destas aos filhos em casa, sob proposta ou orientação da primeira. Este aspeto é "uma face mais "democrática" e de "abertura" da escola ao meio" (Silva, 2003, p. 67), sendo que "muitos esquemas de intervenção curricular procuram fazer a casa funcionar como a escola" (Vincent, 1996, como citado em Silva, 2003, p. 68).

Ainda nesta esteira, Silva (2003) afirma que "vivemos numa era de parentização docente e de docentização parental" (p. 389) em que professores e pais "assistem a uma proliferação dos seus papéis e dos seus contextos de intervenção, apelando a novas práticas" (p. 389).

Esta lógica de colaboração só faz sentido se houver partilha de esforços e vontades, porque "pais e professores têm papéis complementares na educação da criança, os primeiros são os educadores de raiz, os segundos intervêm na escolarização, com objectivos latos de desenvolvimento e autonomia" (Sousa, 1998, p. 174).

Para a autora, por vezes, "pais e professores falam uns dos outros sem se conhecerem" (p. 174), todavia, sabemos que para "as mensagens passarem entre os elementos e ser possível negociar e aprender é preciso o contato direto que clarifica intenções" (p. 174). Este aspeto é essencial quando se trabalha com alunos com dislexia.

O trabalho com estes alunos requer uma preparação cuidadosa e de estreita colaboração, entre o professor e o docente de educação especial, os pais e todos os outros parceiros educativos. Uma verdadeira colaboração entre todos os intervenientes pode constituir um fator decisivo no trabalho com estes alunos, uma vez que todos trabalham para o mesmo fim.

A partir do momento em que a escola e a família compreendem as dificuldades e os esforços do aluno, é mais fácil encontrar os recursos que 
possibilitem ajudá-lo a superar os problemas no processo de aprendizagem.

O envolvimento dos pais na escola faz com que a criança se sinta mais integrada e segura e, por sua vez, trazer o ambiente familiar para o quotidiano da escola faculta-lhe um à-vontade na sua expressão e na execução das suas competências.

Pretende-se, assim, que as vantagens que resultam da colaboração abarquem uma partilha de responsabilidades pelo ensino destes alunos, resultando numa melhor compreensão das suas necessidades, de forma a privilegiar o trabalho em equipa.

Almeida, Ribeiro e Simões (2011) consideram "haver necessidade de um esforço profissional por parte dos professores/escola, atento e empenhado, de forma a criar interrelações humanas que permitam alcançar resultados de sucesso" (p. 242). Partilhamos da opinião das autoras quando frisam que "atualmente, o trabalho com as famílias requer uma prática baseada na parceria educacional" (p. 242).

O processo de negociação é essencial na definição da relação entre pais e professores (Figura 1). Sousa (1998) considera que "pais e professores têm funções idênticas (transmitir conhecimentos e promover a socialização/autonomia), com papéis diferentes" (p. 175). Enquanto espaço educativo, a escola "tem de manter um elo forte com a família para que a educação tenha ressonância no aluno" (p. 176), pois sabemos que envolver os pais na escola aumenta o rendimento escolar dos seus filhos. É, assim, importante descobrir-lhes competências, capacitá-los e, assim, fazê-los agir (Sousa, 1998).

Figura I

Processo de negociação entre pais e professores (Sousa, 1998, p.176)

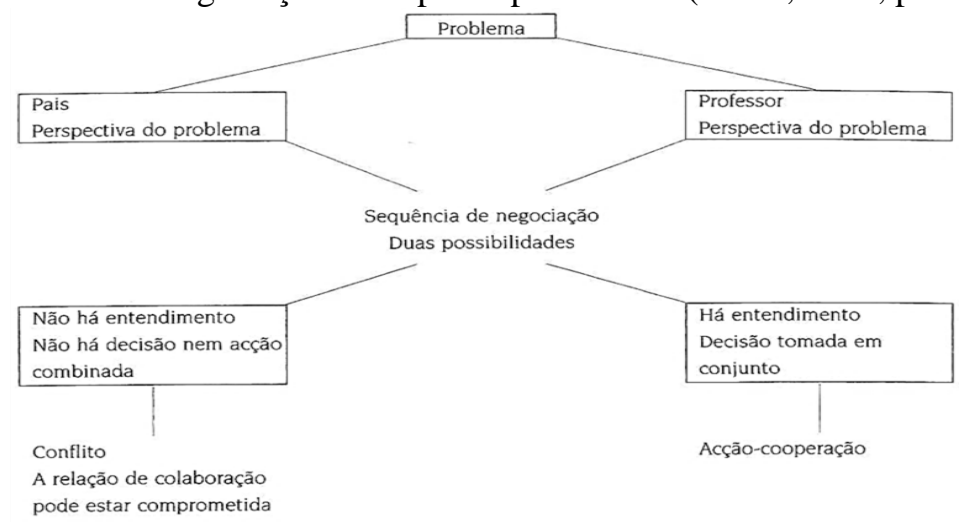


É extremamente importante que pais e professores estejam em constante comunicação, visto que é a única forma de garantir o rigor e a qualidade do trabalho. Há, assim, segundo Silva (2007), "uma grande necessidade de atividades diversificadas que envolvam tanto a expressão corporal como o sabor, o cheiro, a cor e a expressão plástica. Aprender não é falar sobre, é fazer!" (p. 44), porque "para aprender bem, é necessário estar envolvido" (p. 56).

Em suma, trabalhar com alunos com dislexia é saber acompanhar e compreender as suas dificuldades, para poder adaptar os conteúdos às características de cada um. É neste sentido que a interação entre pais e professores é substancial. A partilha de conhecimentos entre ambos vai melhorar todo o processo de aprendizagem. Assim, entende-se como extremamente necessário um diálogo contínuo e compreensão entre os docentes e os pais. Nesta esteira, Paiva (2014) vê como fundamental que a dislexia seja trabalhada "com esforço, dedicação, resiliência, paciência e estratégias diversificadas e com a articulação de trabalho conjunto entre pais e família", visto que "só desta forma será possível combater as dificuldades e frustração decorrentes da dislexia” (p. 145).

\section{ESTRATÉgIAS A USAR PELOS PAIS JUNTO DOS FILHOS COM PERTURBAÇÃO DA APRENDIZAGEM ESPECÍFICA COM DÉFICE NA LEITURA}

Do ponto de vista legal tem havido um avanço muito significativo, no que diz respeito à participação dos pais na escola. A LBSE - Lei n. ${ }^{\circ}$ 46/86, de 14 de outubro, é disso exemplo e refere a responsabilidade da família na tarefa de educar. Esta é quem adota o papel principal na educação dos seus filhos, segundo este normativo, colaborando posteriormente com a escola e permitindo que os seus educandos obtenham um maior sucesso. Assim, quando há partilha de responsabilidades, parte-se do pressuposto que "o sucesso educativo de todos só é possível com a colaboração de todos" (Diogo, 1998, p. 74) e a família é peça fundamental, visto que, segundo Pourtois e Desmet (1991, como citados em Diogo, 1998), "as famílias não são mais receptáculos passivos, mas pessoas, ou seja, experts possuindo recursos educativos potenciais que podem ser actualizados" (p. 74).

Para os professores, a maioria dos pais demite-se do seu papel educativo, delegando na escola a educação dos seus filhos. Por outro 
lado, os pais veem os professores como especialistas capazes de educar os seus educandos. Julgamos que pais e professores não devem estar sozinhos neste desafio, devem antes estar juntos, porque para que a sua relação seja fértil e positiva, deve estar alicerçada no que Marujo, Neto e Perloiro (2005) chamam de regra dos três "Cês", isto é, "na Confiança, na Cooperação e na Comunicação" (p. 152). Neste sentido, dizem os autores, os pais devem perguntar ao professor aquilo que acham que podem, como mãe ou pai, fazer em casa para apoiar o filho nas atividades escolares. Se bem que não se devam tornar nos professores dos próprios filhos, podem ser os adultos que mais ajudam, acelerando os progressos dos educandos (Shaywitz, 2008). Para a autora, quando chegam a casa, tanto os pais como os filhos "não estão no seu momento mais energético ou paciente" (p. 233), recomendando, desta forma, um trabalho de quinze a vinte minutos.

Admitimos que "nem todas as famílias se sentem preparadas para assumir atitudes pedagógicas deste tipo. Contudo, se o professor e os pais acertarem as práticas educativas neste âmbito, pensamos ser possível maior sucesso" (Henriques, 2007, p. 218).

Neste sentido, também Marujo, Neto e Perloiro (2005) avançam que o apoio que os pais podem prestar aos filhos vai além dos conteúdos. Referem que, independentemente dos conhecimentos escolares ou do nível de escolaridade que os pais possuem, estes podem sempre orientar e estimular o educando a ser um aluno equilibrado e a aprender.

Assim, as autoras supracitados, à semelhança de Hennig (2003) e de Selikowitz (2010), consideram ser realmente importante que os pais:

- se interessem vivamente pela vida escolar do seu educando, pela sua aprendizagem, pelos seus resultados.

- mostrem que acreditam nas suas capacidades e esperam dele todo o esforço para atingir o seu melhor.

- estabeleçam com a escola uma relação positiva e frequente.

- o auxiliem para que tenha um bom local de estudo, num espaço organizado e sem estímulos distrativos, estruture e cumpra um horário de estudo e corresponda às exigências da escola (trabalhos de casa, material, etc.).

- o ajudem a aprender estratégias de estudo.

- o recompensem e elogiem pelo esforço e bons resultados (os melhores que for capaz de dar, evitando conotar-lhe a aprendizagem com negatividade, críticas, ansiedades, inseguranças. 
- o rodeiem de um clima emocional e de um estilo de vida que o motive para aprender, descobrir, explorar, saber.

- lhe proporcionem, se e quando necessário, apoio externo para se sentir feliz e dar o seu melhor.

- o entusiasmem a ler, escrever e descobrir o mundo, levando-o a ter objetivos que passem pela aprendizagem e a acreditar e saborear os seus mais pequenos sucessos pessoais.

- lhe ofertem todo o tempo que disponha, de uma forma interessada e atenta.

- lhe proporcionem um ambiente em que a saúde física e mental sejam apoiadas, desenvolvidas e modeladas.

- continuem do seu lado mesmo quando falha, tem insucesso, tem receios e ansiedades ou é diferente da maioria dos outros.

- o ajudem, diariamente, a acreditar que a vida vale a pena e que os problemas existem para os resolvermos (Marujo, Neto \& Perloiro, 2005).

Portanto, é importante que as famílias construam o que Epstein (s.d., como citada em Diogo, 1998, p. 136) designa de "positive home conditions", como ponto de partida para o sucesso de uma criança disléxica. É necessário apoiá-la na organização do estudo e que não se adote o facilitismo, mas também é fundamental não impor regras muito rígidas de métodos de estudo. Os métodos poderão mesmo ser encontrados dialogando com a criança, para que ela refira quais as suas reais dificuldades. Desta forma, poder-se-á dar mais enfoque a estratégias ativas que permitirão que a criança possa gerir as suas próprias dificuldades, ficando mais consciente das áreas onde residem as suas dificuldades, conseguindo, deste modo, desenvolver capacidades de autocorreção.

Os pais podem ajudar os filhos na elaboração de um horário semanal que deve ser "pessoal, realista e flexível, elaborado de acordo com as necessidades dos filhos e não à medida da ambição dos pais" (Estanqueiro, 2013, p. 82).

A criança deverá ser incentivada a cultivar a sua autonomia, uma vez que, uma criança disléxica, devido à sua perturbação, desenvolve, muitas vezes uma baixa autoestima; esta aquisição de autonomia gradual, fará com que, com o passar do tempo, a baixa autoestima vá desvanecendo. Para isso, é essencial que os pais confiem nos seus filhos, acreditando que eles são capazes de crescerem e de se tornarem o mais independentes possível. 
Neste sentido, Shaywitz (2008) defende que a criança disléxica "necessita de um campeão, alguém que seja o seu apoio e incondicional defensor, que a anime, quando as coisas não estão a correr bem, que seja seu amigo e confidente" (p. 190). Segundo a autora, é fundamental que o leitor em dificuldades tenha alguém

que não só acredite nele como traduza essa confiança em acções positivas, ao compreender a natureza do respetivo problema de leitura para, de seguida, trabalhar de forma activa e incessante de assegurar que o sujeito recebe a ajuda de que necessita, tanto no respeitante à leitura como a qualquer outro tipo de apoio que seja necessário (Shaywitz, 2008, pp. 190-191).

A autora afirma, ainda, que "uma criança que conta com um tal apoio não só será academicamente bem-sucedida como manterá um equilibrado sentido de si e ver-lhe-á serem abertas as possibilidades de uma vida futura feliz" (Shaywitz, 2008, p. 191).

Os resultados da investigação demonstram que os trabalhos de casa são um facilitador da relação entre pais e professores, o que vai ao encontro da opinião destes. Julga, ainda, que se revela uma atividade que tão bem traduz o envolvimento dos pais na escolaridade dos filhos (Montandon, 1991). A autora concluíu que grande parte dos pais se envolve nos trabalhos de casa, controlando, vigiando ou dando a sua ajuda.

Geralmente é a mãe quem auxilia o trabalho escolar dos filhos em casa e o apoio prestado varia consoante o seu nível de escolarização. Segundo a autora, as famílias que têm um fraco nível de instrução raramente prestam auxílio aos filhos na realização dos trabalhos de casa. Clarifica, ainda, que a participação dos pais e o tempo que estes dedicam aos trabalhos de casa dos filhos, tem em conta o ano de escolaridade em que o aluno está. Montandon (1991) menciona que o acompanhamento prestado pelos pais é maior até ao $3^{\circ}$ ano de escolaridade.

Somos conhecedores do infindável debate sobre os trabalhos para casa (TPC), que, segundo um relatório da Organização para a Cooperação e Desenvolvimento Económico (2014) (OCDE) e Rønning (2011), contribuem para o aumento das desigualdades socioeconómicas nos resultados dos alunos. Dados recolhidos pela organização demonstram que os alunos provenientes de meios socioeconómicos mais favorecidos, relativamente aos seus colegas provenientes de meios mais desfavorecidos, dedicam, em média, duas horas por semana a estas atividades, no caso português, obtendo daí melhores desempenhos escolares. 
Zenhas (2006) sublinha que, independentemente das habilitações académicas ou do estatuto socioeconómico dos encarregados de educação, o acompanhamento do estudo feito pela família é mais abrangente e exequível. Para a autora, "a influência da família na aprendizagem escolar depende das actividades e atitudes promotoras de aprendizagem que eles desenvolvem e têm com os filhos" (p. 164).

Contudo, é essencial sublinhar a importância dos TPC, desde que estes sejam relevantes e relacionados com os objetivos de aprendizagem. Entre outros benefícios, os TPC promovem bons hábitos de estudo, ajudam a consolidar e esclarecer o que foi aprendido durante o horário escolar, permitem a prática com conteúdo de conceitos e competências, melhoram o desempenho dos alunos nos testes de avaliação, reduzem o tempo despendido a ver televisão e jogar computador, e incutem e ensinam a autodisciplina, a responsabilização e a gestão/organização do tempo.

A este propósito, Marujo, Neto e Perloiro (2005) acreditam que os TPC existem diariamente com a finalidade de "levar os alunos a praticar, fortalecer e reforçar conteúdos e competências escolares e auxiliar os professores a avaliarem quão bem está o aluno a compreender uma determinada temática" (p. 113). As autoras citadas, assim como Estanqueiro (2013), creem que a prática dos TPC promove valores como a independência, autodisciplina, iniciativa, gestão de recursos e de tempo, sentido de responsabilidade e competência.

Marques (2001) e Patton (1994) consideram que o papel da família relativamente à realização dos TPC é, de certa forma, limitado, uma vez que a sua intervenção deve ser no sentido de criar um ambiente favorável que estimule a concentração do aluno, o ajude a determinar um tempo próprio, ou na obtenção de material necessário. Salientam, também, que o apoio dos pais deve ser utilizado apenas no reforço do que é ensinado na escola, devendo os pais fazer uma supervisão constante dos trabalhos dos filhos, mantendo um contato direto com a escola que facultará orientações ou formação relativas aos procedimentos a adotar.

Por sua vez, também Shawitz (2008) considera que a casa é o local ideal para a prática e para o reforço, uma vez que as novas aprendizagens cabem à escola. Em casa, estas aprendizagens devem apenas ser consolidadas. Para isso, é importante que os pais trabalhem em articulação com os professores dos filhos, como temos vindo a referir, para garantir que todos estão a trabalhar em sintonia. A autora sugere que os pais devem perguntar "ao professor que atividades específicas estão a 
ser realizadas na sala de aula e de que forma pode, em casa, ajudar a desenvolver as competências de leitura da criança" (p. 205). Nesta esteira, também Villas-Boas (2000) salienta ser importante que

os professores tomem a iniciativa de contactar os pais e os levem a compartilhar com os filhos e com os próprios professores as responsabilidades da aprendizagem. Embora muitos pais tenham pouca confiança nas suas capacidades, eles devem aperceber-se e convencer-se que podem, efectivamente, ajudar os seus filhos (p. 6).

Com os pais a trabalhar fora, é frequente que estes tenham horários muito preenchidos e, por vezes, não haja tempo disponível para que o pai ou a mãe trabalhem de forma regular com o seu educando. Todavia, há atividades que podem ser também realizadas com a ajuda de um tutor, como refere Hennig (2003). Este pode ser um irmão ou um amigo que podem "ajudar a criança disléxica a desenvolver estratégias que eventualmente a ajudarão a realizar o trabalho de casa por si mesma" (p. 32). Cronin (1994, como citado em Hennig, 2003) sugere algumas orientações para que a criança com dislexia realize os TPC e, desta forma, se sinta menos frustrada e mais bem-sucedida:

1. Estabelecer uma rotina. $\mathrm{O}$ trabalho de casa deve ser feito todos os dias, a uma hora específica.

2. Definir um local. Este local de trabalho deve ser confortável, sossegado, sem acesso à televisão, com boa iluminação e, de preferência, deve ter uma secretária.

3. Dividir os trabalhos em etapas.

4. Nunca usar o trabalho de casa como castigo (p. 33).

Como os alunos com dislexia precisam de estruturação e de organização nas suas vidas, é essencial que se tente estabelecer uma rotina, porque cria um hábito e promove a responsabilidade. O trabalho deve, ainda, ser fracionado, visto que a criança com dislexia tem dificuldade em seguir passos longos e complicados (Hennig, 2003; Patton, 1994).

Assim, no processo inicial da aquisição da leitura, os pais parecem desempenhar um papel fundamental, uma vez que são "os adultos que, pelo afecto e pela proximidade, mantêm, normalmente, com a criança uma relação privilegiada" (Villas-Boas, 2000, p. 7). Desta forma, a autora acredita que "tanto os pais como os professores parecem estar de acordo quanto ao facto de que, na leitura, é importante começar cedo e bem" ( $p$. 7) e "os pais devem ser entendidos como um recurso que permite um sucesso continuado na aprendizagem da leitura e da escrita" (p. 10). 
Reforçamos a ideia de que em casa se devem reforçar competências e desenvolver a leitura, sobretudo no que respeita aos alunos disléxicos. Há, desta forma, variadas hipóteses de jogos e estratégias lúdicas que permitem trabalhar com estes alunos as questões que envolvem a leitura. Estas atividades realizadas em casa apoiam a instrução proporcionada na escola e ajudam o aluno a desenvolver a fluência, a linguagem e o pensamento lógico e crítico. Permitem, ainda, trabalhar a concentração e a criatividade estimular a curiosidade, a iniciativa e a autoconfiança.

Assim, existe uma grande quantidade de manuais escolares, ficheiros pedagógicos de reeducação, manuais de apoio, livros de passatempos, revistas, jogos didáticos, com indicações e exemplos práticos que podem ser utilizados tanto na escola como em casa. Pretende-se, essencialmente, solucionar as dificuldades específicas destes alunos, recolhendo, adaptando ou mesmo construindo as atividades a utilizar (Cf., por exemplo, Hennig, 2003; Ribeiro \& Baptista, 2006).

\section{CONCLUSÃO}

Longe de ser uma questão pacífica, a relação escola/pais acarreta, por vezes, alguns problemas delicados, uma vez que nem sempre é fácil aproximar pontos de vista tão diferentes. Vimos, porém, que atualmente se reconhece que uma boa relação entre pais e professores fomenta o sucesso escolar.

Em educação devemos perguntar-nos que pais/Encarregados de Educação é que queremos: coadjuvantes ou apenas figurantes? Tiraremos muito mais vantagens se tivermos pais responsáveis, colaboradores e parceiros. Estes devem "ser capazes de se considerar a si mesmos enquanto importantes agentes da aprendizagem dos filhos" (Barros, Pereira \& Goes, 2008, p. 88), apoiando as aquisições que a criança realiza na escola, visto que, corroboramos da opinião das autoras, na medida em que são inúmeros os benefícios da participação dos pais na vida escolar dos filhos.

Os filhos, quando sentem que os pais se interessam pela sua escolaridade, ficam mais motivados para a aprendizagem, desenvolvendo atitudes mais positivas. Nos alunos com PAE, este aspeto é igualmente verdade, na medida em que o envolvimento dos pais potencializa o seu sucesso e mais facilmente estes alunos chegam ao máximo das suas potencialidades (Sousa, 1998). 
Salientamos, assim, a importância de um olhar, por parte da escola, diferente para as famílias, pois estas são também fontes de aprendizagem e construtoras de continuidades.

Mas como postula Nóvoa (2005), a escola não pode tudo e, por isso, pretende-se que seja efetuado um trabalho conjunto e planeado entre pais e professores, de forma a desenvolver métodos de estudo, capacidade de autonomia, e sentido de responsabilidade e independência destes alunos. Urge abrir as escolas aos pais, proporcionar comunicação frequente, tratálos como reais membros da comunidade educativa (Davies, Marques \& Silva, 1997). Para estes autores, tem de haver uma mudança de atitude dos docentes, que terão de olhar os pais como educadores capazes também de efetuar intervenções facilitadoras de sucesso educativo. Desta forma, a missão de educar é partilhada por todos.

\section{BIBLIOGRAFIA}

Almeida, C., Ribeiro, C., \& Simões, C. (2011). Trabalho partilhado entre famílias de alunos com Dificuldade Intelectual e Desenvolvimental e os professores: A pertinência e a Atualidade. Revista Gestão e Desenvolvimento, 19, 229-247.

Azcue, J. (2012). A escola onde se aprende. Cascais: Princípia Editora.

Barros, L., Pereira, A., \& Goes, A. (2008). Educar com sucesso - manual para técnicos e pais (2. ${ }^{\mathrm{a}}$ ed.). Lisboa: Texto Editores.

Bronfenbrenner, U. (1979). The ecology of human development: Experiments by nature and design. Cambridge: Harvard University Press.

Correia, L. (2008). Inclusão e Necessidades Educativas Especiais: Um guia para educadores e professores (2. ${ }^{\mathrm{a}}$ ed.). Porto: Porto Editora.

Davies, D., Fernandes, J., Soares, J., Lourenço, L., Costa, L., Villas-Boas, M., Vilhena, M., Oliveira, M., Dias, M., Silva, P., Marques, R., \& Lima, R. (1989). As Escolas e as Famílias em Portugal realidade e perspetivas. Lisboa: Livros.

Davies, D., Marques, R., \& Silva, P. (1997). Os professores e as famílias: A colaboração possível. Lisboa: Livros Horizonte.

Diogo, J. (1998). Parceria escola-família: A caminho de uma educação participada. Porto: Porto Editora.

Estanqueiro, A. (2013). Comunicar com os filhos - o papel dos pais na educação. Lisboa: Editorial Presença. 
Hennigh, K. (2003). Compreender a Dislexia - um guia para pais e professores. Coleção Educação e Diversidade. Porto: Porto Editora.

Henriques, M. (2007). Os trabalhos de casa na escola do $1^{\circ}$ ciclo da luz: estudo de caso. In P. Silva (Org.), Escolas, famílias e lares. Um caleidoscópio de olhares (pp. 211-230). Porto: Profedições.

Marques, R. (1991). A Escola e os Pais - Como Colaborar? Lisboa: Texto Editora.

Marques, R. (1997). Envolvimento dos pais e sucesso educativo para todos: o que se passa em Portugal e nos Estados Unidos da América. In D. Davies, R. Marques, \& P. Silva (Orgs.). Os professores e as famílias: a colaboração possível (pp. 23-48). Lisboa: Livros Horizonte.

Marques, R. (2001). Educar com os pais. Lisboa: Editorial Presença.

Marujo, H., Neto, L., \& Perloiro, M. (2005). A família e o sucesso escolar ( $4^{\mathrm{a}}$ ed.). Lisboa: Edições Científica Editorial Presença.

Montandon, C. (1991). L'école dans la vie des familles. Ce qu'en pensent les parents des élèves du primaire genevois. Genève: Cahiers du service de la recherche sociologique.

Montandon, C. (1996). Les relations des parents avec l'école. Revue internationale d'action communautaire, 35, pp.63-73.

Nóvoa, A. (2005). Evidentemente - Histórias da Educação. Porto: Edições ASA.

OECD (2014), "Does Homework Perpetuate Inequities in Education?", PISA in Focus, N. ${ }^{\circ}$ 46, OECD Publishing, Paris.

Paiva, R. (2014). O segredo para alcançar o sucesso na escola. Lisboa: A Esfera dos Livros.

Patton, J. (1994). Practical Recommendations for Using Homework with Students with Learning disabilities. Journal of learning disabilities, 27 (9), 570-578.

Ribeiro, A., \& Baptista, A. (2006). Dislexia: compreensão, avaliação e estratégias educativas. Coimbra: Quarteto.

Rønning, M. (2011). "Who benefits from homework assignments?". Economics of Education Review, 30 (1), 55-64.

Sampaio, D. (1996). Inventem-se novos Pais ( $8^{\mathrm{a}}$ ed.). Lisboa: Editorial Caminho.

Selikowitz, M. (2010). Dislexia - os factos. Alfragide: Texto Editores. 
Shaywitz, S. (2008). Vencer a Dislexia: Como dar resposta às perturbações da leitura em qualquer fase da vida. Porto: Porto Editora.

Silva, F. (2007). Lado a lado - experiências com a dislexia. Lisboa: Texto Editores.

Silva, P. (2003). Escola-Família, uma relação armadilhada Interculturalidade e relações de poder. Porto: Edições Afrontamento.

Sousa, L. (1998). Crianças (Con)Fundidas entre a escola e a família. Uma perspectiva sistémica para alunos com necessidades educativas especiais. Porto: Porto Editora.

Villas-Boas, M. (2000). A parceria entre a escola, a família e a comunidade - Trabalhos de casa para o desenvolvimento da literacia. Lisboa: Ministério da Educação, Departamento da Avaliação Prospetiva e Planeamento, PRODEP.

Zenhas, A. (2006). O Papel do Director de Turma na Colaboração Escola-Família. Porto: Porto Editora.

\section{LEGISLAÇÃO}

Lei n. ${ }^{\circ}$ 46/86, de 14 de outubro - Lei de Bases do Sistema Educativo 